\title{
A low dose of albuterol (salbutamol) by metered dose inhaler (MDI) with a spacer was as effective as higher doses by MDI or low doses by nebuliser in children with mild acute asthma
}

Schuh S, Johnson DW, Stephens D, et al. Comparison of albuterol delivered by a metered dose inhaler with spacer versus a nebulizer in children with mild acute asthma.J Pediatr 1999 Jul;135:22-7.

QUESTION: In children with mild acute asthma, is albuterol (salbutamol) delivered by a metered dose inhaler (MDI) with a spacer (standard low dose or higher, weight adjusted dose) as effective as albuterol delivered by a nebuliser?

\section{Design}

Randomised (concealed), blinded (patient and outcome assessor), controlled trial.

\section{Setting}

A hospital emergency department in Toronto, Ontario, Canada.

\section{Patients}

90 children who were 5-17 years of age (mean $9.2 \mathrm{y}$, mean baseline forced expiratory volume in 1 second $\left[\mathrm{FEV}_{1}\right] 62.8 \%$ ) who presented with acute asthma exacerbation between 0800 and 2200, could reliably perform pulmonary function testing, and had a baseline $\mathrm{FEV}_{1}$ of $50 \%-79 \%$ of the predicted value. Children were excluded if this was their first wheezing episode, they had used albuterol within 4 hours of the visit, had concurrent cardiopulmonary disease, or had hypersensitivity to albuterol.

\section{Intervention}

30 children were allocated to a standard low dose of albuterol by MDI with a clear plastic $140 \mathrm{ml}$ spacer device with a mouthpiece ( 2 puffs, $100 \mu \mathrm{g} /$ puff) and 30 children were allocated to a higher, weight adjusted dose of albuterol by MDI with a spacer (6-10 puffs [100 $\mu \mathrm{g} / \mathrm{puff}]$ depending on weight). The MDIs were shaken between each puff, and the children took 5-6 normal breaths through the mouthpiece between each puff. 30 children were allocated to albuterol $0.15 \mathrm{mg} / \mathrm{kg}$ (maximum $5 \mathrm{mg}$ ) by jet nebuliser with a tight fitting plastic face mask. Albuterol mixed with $3 \mathrm{ml}$ of normal saline solution was given by the nebuliser with an oxygen flow of $6-8 \mathrm{l} / \mathrm{min}$ over a 15-20 minute period. To ensure patient blinding, each child used 2 MDIs and a nebuliser (ie, the allocated treatment dose and 2 placebo doses).

\section{Main outcome measures}

Primary outcome was percent predicted $\mathrm{FEV}_{1}$ measured with a hand held spirometer. Secondary outcomes included respiratory rate, heart rate, oxygen saturation (room air), and scores for accessory muscle, wheezing, and dyspnea. Outcomes were assessed before treatment and 30,60, and 90 minutes after treatment.

\section{Main results}

Analysis was by intention to treat. The 3 groups had similar mean changes from baseline to 90 minutes for $\mathrm{FEV}_{1}(\mathrm{p}=0.12)$, respiratory rate $(\mathrm{p}=0.98)$, oxygen saturation, and scores for accessory muscle $(p=0.58)$, wheezing $(\mathrm{p}=0.73)$, and dyspnea $(\mathrm{p}=0.39)$. Children in the nebuliser group had a higher mean increase in heart rate than children in the 2 MDI groups (increase of 12.9 beats/min $v 3.4$ for high dose MDI and 2.6 for low dose MDI, $\mathrm{p}=0.005$ )

\section{Conclusion}

In children with mild acute asthma, treatment with a standard low dose of albuterol (salbutamol) by metered dose inhaler (MDI) with a spacer was as effective as treatment with higher, weight adjusted doses delivered by MDI with a spacer or low doses delivered by a nebuliser.

\section{COMMENTARY}

The US National Asthma Education and Prevention Program Expert Panel Report guidelines indicate that equivalent bronchodilation can be obtained by MDI with a spacer as with continuous nebuliser treatment. ${ }^{1}$ This study by Schuh et al adds to the increasing evidence that children with mild asthma derive similar clinical benefit from bronchodilators delivered by MDI with a spacer or by a nebuliser. A recent systematic review of 13 trials in adults and children concluded that MDIs with spacers were at least as effective as nebulisers for $\beta$-agonist administration, and in children, resulted in shorter stays in the emergency department and lower pulse rates.

The study design addresses weaknesses in previous clinical studies by comparing high and low doses of medication delivered by MDI with a spacer with delivery of a low dose of the same medication by nebuliser. Blinding the children to which treatment they received (by having them use 2 MDIs and a nebuliser, 2 of which contained placebos) and blinding the research nurses who measured the outcomes increase the trustworthiness of the findings. The authors did not describe how the assessment scores (wheezing, accessory, and dyspnea) were derived, which limits the interpretation of these data However, the main research question is answered by improvements in a standardised measure $\left(\mathrm{FEV}_{1}\right)$.

The results are relevant for advanced practice nurses (paediatric nurse practitioners and clinical nurse specialists) who manage children's asthma in emergency departments, urgent care centres, or specialty clinics. Matching treatment strategies in the acute care setting with those used at home can increase family compliance with the treatment plan ${ }^{3}$ by providing nurses with an opportunity to (1) assess family and child techniques (MDI, nebuliser, peak flow, and spirometry); (2) demonstrate proper techniques or refine family techniques; (3) answer questions; and (4) verify family learning with return demonstration before they are discharged to home care.

Sharon D Horner, RN, PhD Assistant Professor, School of Nursing The University of Texas at Austin Austin, Texas, USA

1 US Department of Health and Human Services. Practical guide for the diagnosis and management of asthma. Bethesda, MD: National Heart, Lung, and Blood Institute, 1997.

2 Cates CJ. Holding chambers versus nebulisers for $\beta$-agonist treatment of acute asthma. (Cochrane Review, latest version 13 Feb 1998). In: Cochrane Library. Oxford: Update Software.

3 Newhouse MT. Asthma therapy with aerosols: are nebulizers obsolete? A continuing controversy. J Pediatr 1999;135:5-8.
Sources of funding: Physicians'Services Incorporated; Trudell Medical; Hospital for Sick Children

Foundation; Department of Pediatrics, Hospital for Sick Children.

For correspondence: Dr S Schuh, Emergency Department, The Children, 555 University Avenue, Toronto, $O N$ M5G 1 X8, Canada. Fax +14168135043 . 